Journal of Applied Fluid Mechanics, Vol. 14, No. 6, pp. 1635-1642, 2021. Available online at www.jafmonline.net, ISSN 1735-3572, EISSN 1735-3645. https://doi.org/10.47176/jafm.14.06.32491

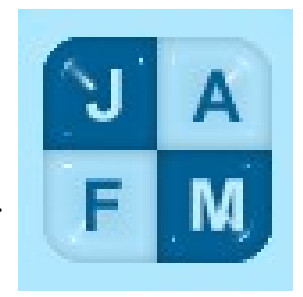

\title{
Effect of a Pylon Mounted Cavity-Based Flameholder on the Combustor Flow Characteristics
}

\author{
S. Nayal ${ }^{1}$ and D. Sahoo ${ }^{2 \dagger}$ \\ ${ }^{1}$ Annasaheb Dange College of Engineering and Technology, Ashta - 416301, Maharashtra, India \\ ${ }^{2}$ Department of Aerospace Engineering, MIT School of Engineering, MIT ADT University, Pune - 412201, \\ Maharashtra, India \\ $†$ †orresponding Author Email: devtapu@gmail.com
}

(Received December 19, 2020; accepted April 28, 2021)

\begin{abstract}
This paper aims to study the effect of a pylon mounted cavity-based flameholder on the combustor flow characteristics. Computational analysis of two different models of flameholder configurations is performed. The novel cavity design 110_90 has a fore-wall ramp angle of 110 degrees and an aft-wall ramp angle of 90 degrees and this design which shows a comparatively better combustor performance is adopted and mounted with a pylon. The flow features over the high performance base cavity 110_90 is compared with the flow features obtained by adding a pylon on the upstream of the base cavity. The two cases are compared qualitatively as well as quantitatively based on the temperature distribution, pressure distribution, recirculation zones and drag experienced by the model. These compared parameters helped us to identify whether the mentioned combination is favorable and augments the flameholder performance.
\end{abstract}

Keywords: Supersonic flow; Combustor performance; Cavity flow; Flameholder.

\section{INTRODUCTION}

Supersonic combustion is an active area of research due to its high importance in propulsion systems of high speed vehicles (Choubey et al. 2019). This area of research finds its best usage in the Scramjet engine which operates at Mach numbers greater than 5. In a Scramjet engine, the combustor encounters supersonic airstream which increases the complications of combustion as it is difficult to sustain a flame in supersonic flows. Flameholding refers to the mechanism in which the upstream charge gets preheated by combustion products due to diffusion (Cain 2002). This mechanism is especially difficult due to the relatively higher speeds of the freestream flow as compared to the flame speeds. Higher flow speeds lead to extremely small residence time for fuel-air mixing and combustion within a reasonable combustor length. To combat this issue, different types of flameholders are used like cavity, struts, and pylons of different shapes (Kyungjae 2012). In search for better flow properties to achieve an enhanced combustion performance, various models have been adopted utilizing more than one type of flameholder simultaneously. It is a common belief that combination of a few compatible flameholders can lead to the augmentation of the performance of the whole setup.
A cavity-based flameholder tends to increase the residence time for fuel-air mixing by creating low speed vortices, as shown in Fig. 1. These vortices or recirculation zones provide high pressure and temperature region for the air to mix with fuel in appropriate proportion within smaller combustor lengths. The relative ease of construction of cavities in combustor walls also makes them a favorable choice as a flameholder. In-depth computational and experimental research has been carried out on different cavity flameholders as a standalone system (Gugulothu 2019). Ouzi Lui (2010) computationally studied the cavity characteristics in a reacting and non-reacting flow and concluded that the cavity flow depends on the size of the recirculation zones, L/D ratio, freestream Mach number and combustion reaction. Exemplary studies have been successfully conducted on different flameholders, especially cavity-based and pylon-cavity based by Gruber et al. (2001); Gruber et al. (2004) and Gruber et al. (2008), both experimentally and computationally. They reported that when the cavity is geometrically similar to a backward-facing step, i.e. having small aft-wall ramp angles, a higher drag coefficient and smaller residence time is noticed.

A three-dimensional pylon case was studied by Freeborn et al. (2009) on an inclined cavity flameholder with swept leading-edge pylon. They 


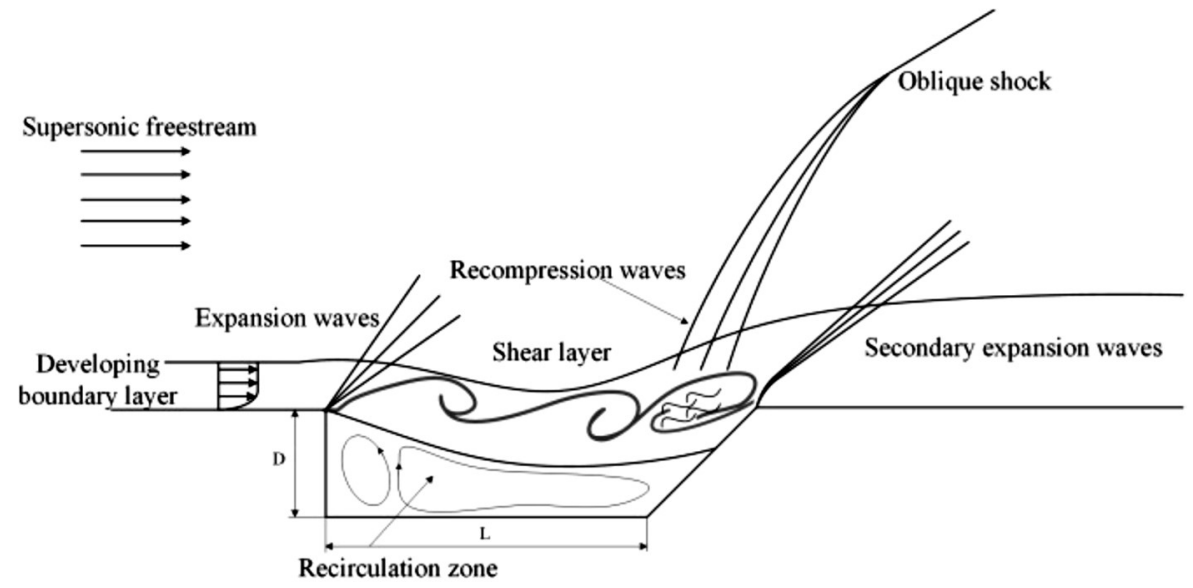

Fig. 1. Flow physics of a cavity-based flame holder (Vishnu et al. 2019).

reported an increase of mass flow rate by 3 times due to the introduction of a pylon to the cavity-based flameholder. Experimental testing was carried out by Liu et al. (2019) on pylon-aided fuel injection and a mixing enhancement due to pylon usage was reported.

Later, Haubelt et al. (2006) experimentally studied the mixing efficiency of a pylon-cavity configuration on various models. Pylon and strut effect on multiple cavity configuration were conducted by Ouyang et al. (2014) experimentally and an increased mixing and combustion effect due to pylon and strut was reported. Fuel injection studies were carried out on multiple cavities by Pan Yu et al. (2014). They found that increasing the pressure of fuel injection leads to more distribution area and the tandem cavities showed better flame stabilization results.

The review paper by Ben-Yakar and Hanson (2001) provides useful insights to some common questions on flameholders and factors affecting its performance. Other studies related to cavities have also been reported in open literature. In the authors' previous work (Nayal et al. 2020), they introduced novel cavity designs by modification of the fore-wall ramp angles. The novel designs were computationally tested and it was identified that a cavity with a fore-wall inclination angle of 110 degrees was an ideal flameholder design amongst other cavities that were tested. These insights encouraged the authors to introduce a twodimensional pylon on the novel cavity designs adopted in their previous study. In the present investigation, the effect of an upstream pylon mounted cavity-based flameholder on the combustor flow characteristics has been studied using 2D computations for a freestream Mach number of 3.0. The flowfield developed in a fore-wall inclined (110 degrees) cavity flameholder has been compared with that generated by mounting a pylon in the upstream of the fore-wall inclined cavity.

\section{MODEL GEOMETRY}

The preliminary designs of the cavity only configuration and the cavity-pylon configuration is shown in Fig. 2. In this model, the cavity-only design is indicated in black and the pylon is indicated in orange colored continuous lines. The cavity is defined by its length and depth represented by L $(26.7 \mathrm{~mm})$ and $\mathrm{D}(8.9 \mathrm{~mm})$, respectively. The forewall ramp angle of the cavity is represented as $\theta_{\mathrm{f}}$, and the aft-wall ramp angle as $\theta_{\mathrm{a}}$. The pylon is defined by an angle $\beta$ and height of pylon, $h_{p}$ as per the specifications provided in Freeborn et al. (2009). The pylon height-to-cavity-depth ratio $\left(h_{p} / D\right)$ is 2.0 , and the pylon angle or $\beta$ is $29^{\circ}$ from the positive $X$ axis. Therefore, the values for $\theta_{\mathrm{f}}, \theta_{\mathrm{a}}$, and $\beta$ adopted in the present study are $110^{\circ}, 90^{\circ}$ and $29^{\circ}$, respectively. Computational analysis of supersonic flow over cavity-only design is compared with the pylon-cavity design for various performance parameters.

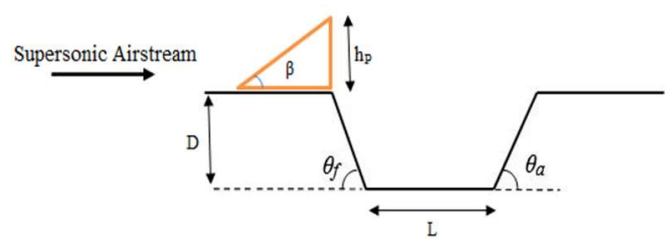

Fig. 2. Geometrical representation of the Cavity and Pylon design.

According to Gruber et al. (2001), the desirable performance parameters for any flameholder design are:

- High pressure distribution

- High temperature distribution

- Large eddies or recirculation zones

- Low drag force on the cavity

\section{Computational Methodology}

Two-dimensional Computational Fluid Dynamics (CFD) simulations are performed using ANSYSFluent software, for steady supersonic viscous flow over the models. A two-dimensional, non-reacting, cold-flow has been considered in the present investigation. An explicit density-based solver, with Green-Gauss cell-based scheme for spatial 
discretization, and Roe-FDS scheme for the inviscid fluxes has been adopted for the present computations. Turbulence model is set to $\mathrm{k}-\omega$, similar to the one adopted in the authors' previous work (Nayal et al. 2020).

The computational investigation performed in the present research is based on the following flow conditions:

- Freestream Mach number: 3.0

- Stagnation pressure: $690 \mathrm{kPa}$

- Freestream Pressure: $18.768 \mathrm{kPa}$

- Stagnation temperature: $300 \mathrm{~K}$

- Freestream Temperature: $107.16 \mathrm{~K}$

- Working fluid: Air (Ideal gas, Sutherland viscosity)

The computational domain, boundary types and typical mesh used in the present research is shown in Fig. 3. The height of the computational domain is about 25 times the cavity depth $\mathrm{D}$ and represents the upper boundary. Similarly, the size of the computational domain in upstream is 10 times the cavity depth, D and in downstream it is 20 times the cavity depth, D. Structured grid with quadrilateral cells having a 1st cell distance of the order $0.01 \mathrm{~mm}$ has been adopted in the present study corresponding to a wall $\mathrm{y}+$ less than 1.0 maintained throughout the computed models. The cavity and pylon region is having $250 \times 200$ cells with total cell count used in the adopted computational domain to be approximately 3.62 lakh.

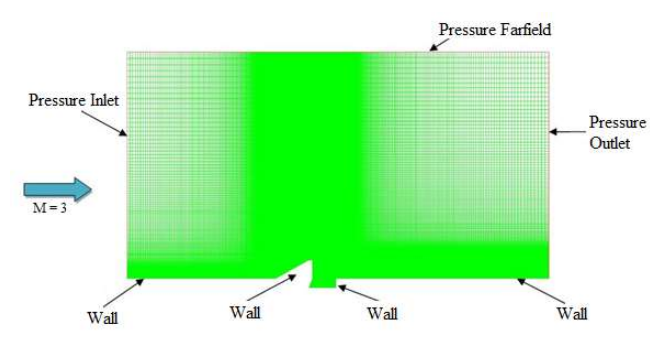

Fig. 3. Computational Domain of the PylonCavity model.

For the pylon cavity model, a buffer region of $30 \mathrm{~mm}$ having fine mesh is kept above the lower wall to capture all the complex flow phenomena precisely.

The residuals from the solutions of the continuity and turbulent kinetic energy equations were monitored during the simulations and only once the residuals were converged to an order of $10^{-5}$, the results were collected for further analysis. Before performing CFD simulation in the present research, suitable solver validation has been conducted and is explained in the subsequent section.

\section{SOLVER VALIDATION}

The experimental result reported over a cavity in
(Gruber et al. 2001) has been utilized for validating the solver adopted in the present investigation. The measured as well as computed data (normalized pressure distribution) for the rectangular cavity design reported in Gruber et al. (2001) is compared with the normalized pressure (ratio of the wall static pressure to the freestream pressure) distribution obtained from the present computation. From the comparison presented in Fig. 4, a satisfactory agreement can be observed between the present computed results with those reported in Gruber et al. (2001), thus, validating our computational methodology and the simulating tool utilized in the present research. Effective distance being the wall surface distance in inches measured from the cavity upstream separation corner along the cavity wall. Convergence to the validation grid was approached after conducting suitable grid independence test.

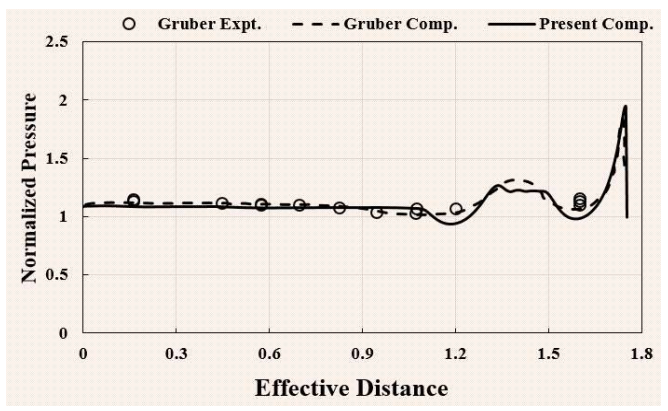

Fig. 4. Comparison of the normalized pressure distribution obtained over the rectangular cavity. Effective distance is the wall surface distance in inches measured from the cavity upstream separation corner along the cavity wall. And Normalized pressure is the ratio of the wall static pressure computed to the free stream pressure.

\section{RESULTS AND DISCUSSIONS}

Steady-State Two-dimensional Computations have been performed at a supersonic freestream Mach number of 3.0 over a fore-wall inclined $\left(110^{\circ}\right)$ cavity flameholder with a pylon mounted in the upstream of the cavity. The flow field developed over the cavity is captured and compared with that obtained over a cavity (fore-wall inclined by $110^{\circ}$ ) without a pylon as reported by the authors' previous work (Nayal et al. 2020). The effect of mounting a pylon at the upstream of the fore-wall inclined cavity is investigated using qualitative as well as quantitative analysis. In order to analyze the effect qualitatively, the contour of normalized pressure, normalized temperature (ratio of static temperature to freestream temperature) and eddy formations captured from the present computations over a pylon based cavity are compared with those obtained over a cavity without a pylon as reported in Nayal et al. (2020). Further, the pressure distribution, temperature distribution, turbulence kinetic energy distribution and drag coefficients generated over these models are also obtained and compared to quantitatively analyze the effect of mounting a pylon on the upstream of the 


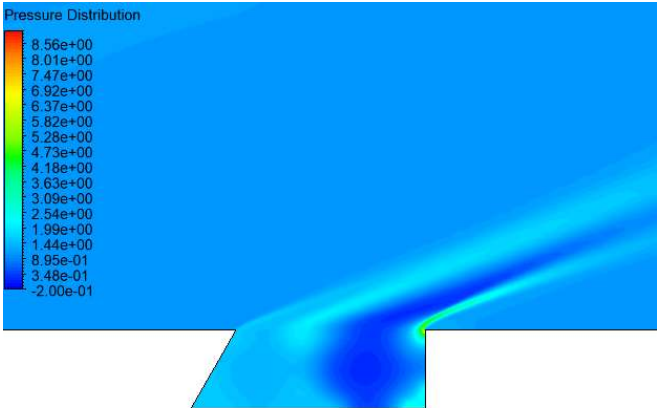

Fig. 5. Normalized pressure contour for cavity-only design (Nayal et al. 2020). Flow is from left to right.

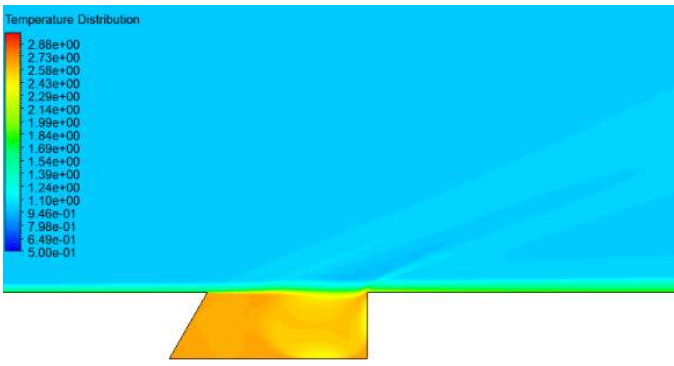

Fig. 7. Normalized temperature contour for cavity-only design (Nayal et al. 2020). Flow is from left to right.

fore-wall inclined cavity based flame holder. The results obtained from the present computations and their comparisons with the reported results (Nayal et al. 2020) are discussed in the following sub-sections.

\subsection{Normalized Pressure}

The Normalized Static Pressure distribution (ratio of the static pressure to the freestream pressure) for the cavity-only and the pylon-cavity designs are computed analytically with respect to the inlet static pressure and shown in Fig. 5 and Fig. 6 respectively.

From the normalized pressure distribution for the cavity-only configuration 11090 , a noticeable increase in the pressure after the separation point at the upper corner of the aft-wall can be observed, indicating a weak shock formation. The aft-wall corner point shows higher pressure than the rest of the cavity. On comparing this with Fig. 6 which shows the normalized pressure distribution for the pylon-cavity configuration of 11090 , the change in the flow features around the cavity model can be observed. It is seen that due to the presence of the pylon, an oblique shock is formed which thereby raises the pressure level on the vicinity of the cavity upstream (over the pylon). The presence of the pylon makes the cavity to fall in the wake region. On close observation, it can be seen that the level of pressure rise at the aft-wall corner of the cavity has reduced in comparison to the cavity-only model. A higher pressure gradient is observed in the presence of the

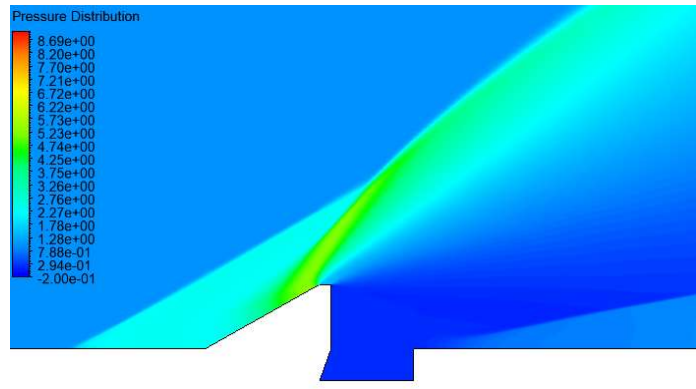

Fig. 6. Normalized pressure contour for pylon- cavity design. Flow is from left to right.

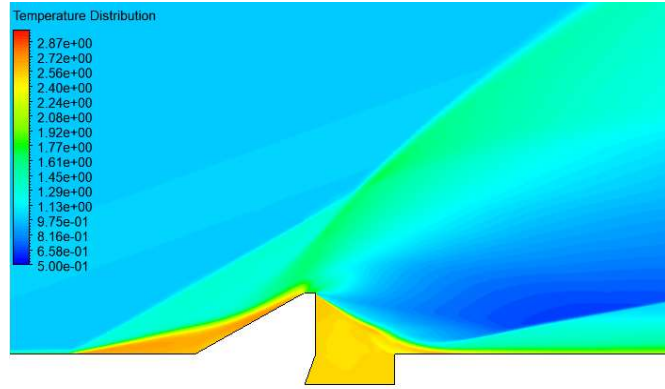

Fig. 8. Normalized temperature contour for pylon- cavity design. Flow is from left to right.

pylon due to the shock formation. The higher pressure distribution favors combustion, however the strong pressure gradients observed over the entire flameholder may enhance the mixing of the incoming charge.

\subsection{Normalized Temperature}

The Normalized Static Temperature distribution (with respect to the freestream static temperature) for the cavity-only and the pylon-cavity designs are obtained analytically as shown in Fig. 7 and Fig. 8 respectively and then compared.

Figure 7 shows the normalized temperature contour for the cavity-only configuration as reported in Nayal et al. (2020). In the case of cavity-only configuration, the shear layer is completely visible and the temperature is found to increase towards the negative $\mathrm{Y}$ axis (downward) from the freestream flow. The temperature increases along the floor of the cavity. A variable temperature contour is observed in the recirculation region formed inside the cavity. For the pylon-cavity model shown in Fig.8, a greater temperature gradient is visible. There is a prominent compression region visible in the pylon region. This leads to high temperatures in the upstream of pylon's base, extending till the tip of the pylon. A strong oblique shock originates from the inclined tip of the pylon, causing increase in temperature across the shock. From the contour, it is clearly visible that the separated boundary layer reattaches itself aft of the cavity. A large recirculation region is visible 


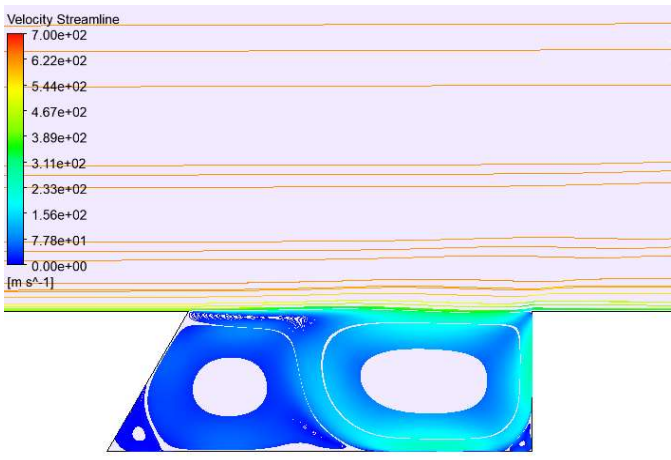

Fig. 9. Recirculation zones visible for cavity-only design (Nayal et al. 2020). Flow is from left to right.

downstream of the pylon which is also favorable for fuel-air mixing. Elevated temperatures near the fuel's auto ignition point may lead to a stable combustion process.

\subsection{Recirculation Zones}

The recirculation zones for the cavity-only and the pylon-cavity designs are computed analytically and analyzed. The velocity streamlines for the cavityonly design presented in Fig. 9, shows strong eddy formation with contours of higher velocities.

On the other hand, the velocity streamlines for the pylon-cavity configuration presented in Fig. 10, shows a larger wake aft-cavity and multiple vortices formation due to the obstruction (mounting of pylon).

The number, magnitude and velocity of the eddies in the pylon-cavity configuration has increased than those produced in the case of standalone cavity system. As the stronger and larger eddies favors mixing and helps in enhancing the combustion efficiency, a better fuel mixing and combustion efficiency can be expected from the pylon-cavity.

In addition to this qualitative analysis, further studies of the quantitative analysis over the two cases were also conducted. The Normalized Pressure, Normalized Temperature and Turbulent Kinetic Energy distributions over the cavity forewall, floor and aftwall were compared in the two cases with the solid green line depicting the cavity-only case and the solid black line depicting the pylon-cavity case in each of the comparison plot (Figs. 11A, 11B and 11C).

Figure 11.A. shows the comparison plot between the two cases based on Normalized Pressure distribution. The normalized pressure for the cavity-only case represented by the green line, shows greater variation on the cavity walls as compared to the pylon-cavity case. The green line reaches a peak value near the upper corner of the cavity aft wall and the normalized pressure decreases along the cavity floor, reaching

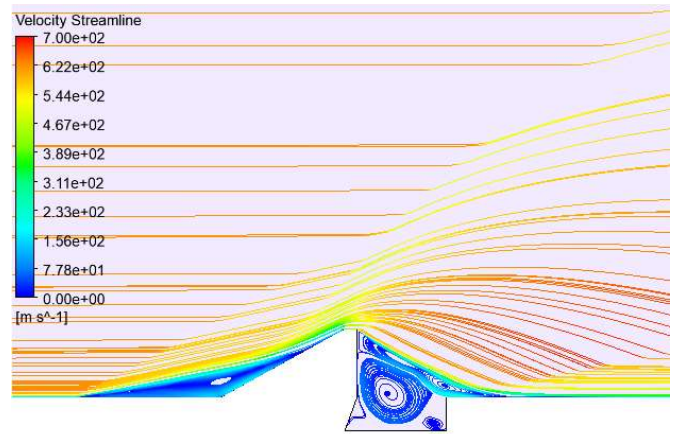

Fig. 10. Recirculation zones visible for pylon- cavity design. Flow is from left to right.

the lowest value near the aftwall. On the other hand, the pylon-cavity case gives more normalized uniform pressure distribution than the cavity-only case but of lesser magnitude. The lesser magnitude might be a result of the larger and faster vortices experienced in the pylon-cavity case.

Figure 11.B. shows the comparison plot between the two cases based on Normalized Temperature distribution. The normalized temperature for the pylon-cavity case is higher than the cavity-only case. Higher temperatures favor combustion so the performance characteristic of the pylon-cavity is better than the cavity-only case.

Figure 11.C. shows the comparison plot between the two cases based on Turbulent Kinetic Energy distribution. It is evident that the magnitude of kinetic energy is more for the cavity-only case especially near the aftwall. A peak is observed near upper corner of the aftwall for both the cases with cavity-only case having greater magnitude.

\subsection{Flameholder Drag}

In order to further quantitatively investigate the effect of mounting a pylon on the upstream of the cavity, the drag force values generated by the cavity models are computed with and without a pylon mounted over it and compared.

It has been observed that the pylon-cavity configuration offers a higher drag force $(1140.8 \mathrm{~N})$ to the system with almost $99.98 \%$ of the drag force being contributed by the pylon. For the cavity-only design, the drag force observed is $78.09 \mathrm{~N}$. The pylon-cavity drag is about 14.6 times greater than the drag force produced by the cavity-only system due to the protruding obstruction provided to the flow of supersonic airstream. It is observed that even if the pylon enhances the mixing of the fuel, it adds on the drag to the entire cavity based flameholder system.

Furthermore, based on the desirable performance parameters mentioned in section 2, the cavity-only and the pylon-cavity configurations are compared in 


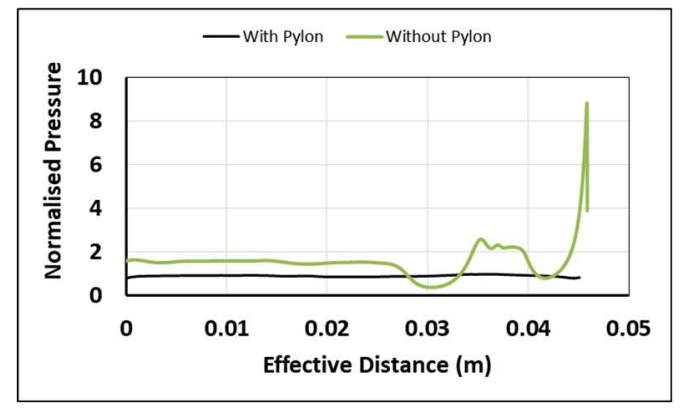

(A)

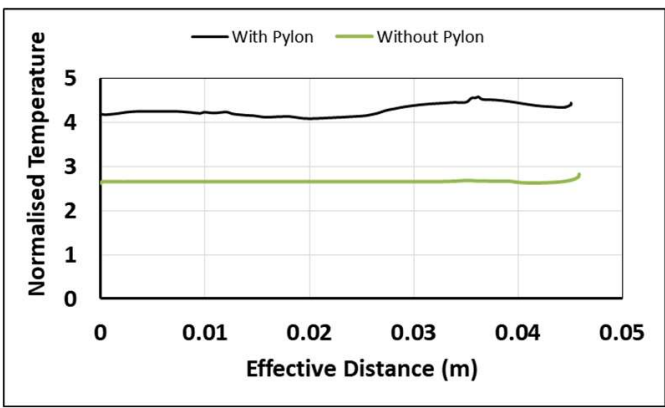

(B)

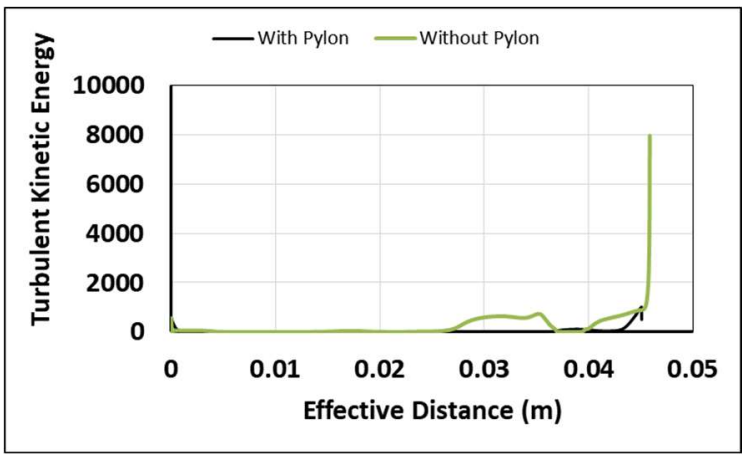

(C)

Fig. 11. (A) Quantitative analysis using Normalized Pressure distribution, (B) Quantitative analysis using Normalized Temperature distribution, (C) Quantitative analysis using Turbulent Kinetic Energy distribution.

Table 1 Comparative performance of the Cavity-only and the Pylon-Cavity designs.

\begin{tabular}{|c|c|c|c|c|}
\hline \multirow{2}{*}{ Configuration } & \multicolumn{3}{|c|}{ Flameholder Performance Parameters } \\
\cline { 2 - 5 } & $\begin{array}{c}\text { Normalized Pressure } \\
\text { Distribution }\end{array}$ & $\begin{array}{c}\text { Normalized Temperature } \\
\text { Distribution }\end{array}$ & $\begin{array}{c}\text { Recirculation } \\
\text { Zones }\end{array}$ & $\begin{array}{c}\text { Flameholder } \\
\text { Drag }\end{array}$ \\
\hline $\begin{array}{c}\text { Cavity-only } \\
110 \_90 \text { (Nayal } \\
\text { et al. 2020) }\end{array}$ & Average & Poor & Average & Average \\
\hline $\begin{array}{c}\text { Pylon-cavity } \\
110 \_90\end{array}$ & Average & Average & Better & Poor \\
\hline
\end{tabular}

detail and tabulated in Table 1. For better understanding, the performance is rated as poor, average and best. The configuration with better performance is chosen as the favorable flameholder design. Based on the detailed comparison presented in Table 1, we see that pylon-cavity design has better overall performance as a flameholder. Pylon-cavity design is superior to the standalone cavity because of average static pressure distribution, higher static temperature distribution and extensive recirculation zones on and around the cavity. These parameters favor combustion and enhance mixing efficiency and residence time. However, a drawback of pyloncavity design is in the form of high drag force. A separate study to investigate a mean to reduce the excessive drag force experienced by the pylon can be considered as the scope of future research.

In addition, an extensive parametric study in the pylon geometry can also be performed along with its effect on the flow unsteadiness arising over the flowfield around the cavity can also be a scope for future research.

The present study proposes a pylon mounted cavitybased flameholder which is similar to the cavity with different fore-wall and aft-wall heights, and it is needed to explain the difference between the two. The size and strength of the recirculation zones in the flowfield plays an important role in flameholder performance. The bigger and stronger the recirculation zone, the better a cavity performs.

For an open cavity case (where ratio of length of the cavity to the depth of the cavity is less than 10), there is difference in flow structure observed between pylon-cavity and cavity with offset ratio $\neq 1$ (offset ratio is the ratio of aft-wall length to the fore wall length). In the case of a pylon-cavity, a large wake is observed downstream of the pylon. It leads to a large 
centralized recirculation zone with height upto $2 / 3$ rd of the pylon. Two additional vortices are observed, one in the cavity (the smaller one) and one above the large central vortex as explained in section 5.3.

In case of a cavity with offset ratio less than one, smaller recirculation zone is visible which is limited to the confines of the cavity. Due to the height difference in the fore-wall and aft-wall, the shear layer slants downwards towards the aft-wall. This further reduces the recirculation zone size, even when compared to a cavity with offset ratio $=1$. So the pylon-cavity case is able to interact with more fluid than a cavity with offset ratio less than 1 . It is also observed that more vortices are produced in the pylon-cavity case which adds to its advantage. Also, the pylon generates strong oblique shock which leads to enhanced shear layer growth. A leading shock of such intensity is absent in the case of any cavity-only configuration.

\section{CONCLUSION}

In the present paper, the combustion performance of a standalone cavity model was compared computationally with a pylon-cavity model. The computational analysis was based on key performance parameters like pressure distribution, temperature distribution, recirculation zones and drag force. Stronger pressure gradients is observed in the flow domain when a protruding obstruction i.e. pylon is added upstream of the cavity.

Higher pressure is observed in the compression region on the angled face of the pylon. Higher pressure distribution favors the combustion process. Due to the compression region upstream of the pylon, high temperature is observed compared to that of the standalone cavity system. This region also may serve to preheat the incoming reactants and aid in flame ignition and stabilization.

In the standalone cavity model, two large vortices are visible in the cavity region. But in the pylon-cavity model, larger wake region is observed downstream the pylon with one large central vortex accompanied by a medium-sized vortex above the larger one. With respect to the size and strength of the recirculation zones, the pylon-cavity model has the upper hand.

It is also observed that the drag force of the pyloncavity design is about 14.6 times higher than the standalone cavity design. The pylon design can be strategically optimized to reduce the drag force to a minimum which will turn this disadvantage into a potential advantage for the pylon-cavity model.

The potential of this pylon-cavity design may further be analyzed with different parameters in order to identify an optimal flameholder configuration. In addition, three dimensional computations can also be conducted in future to get additional insight of the flow characteristics.

\section{REFERENCES}

Ben-Yakar, A. and R. K. Hanson (2001). Cavity Flame-Holders for Ignition and Flame
Stabilization in Scramjets: An Overview. Trans. Journal of Propulsion and Power 17(2), 869-877.

Cain, T. C. W. (2002, July). Review of Experiments on Ignition and Flameholding in Supersonic Flow. In Proceedings of 38th AIAA/ASME/SAE/ASEE Joint Propulsion Conference \& Exhibit, Indianapolis, Indiana.

Devarajan, Y., W. Huang, K. Mehar, M. Tiwari and K. M. Pandey (2019). Recent advances in cavity-based scramjet engine - a brief review. International Journal of Hydrogen Energy 44, 13895-13909.

Freeborn, A. B., P. I. King and M. R. Gruber (2009). Swept Leading Edge Pylon Effects on a Scramjet Pylon-Cavity Flameholder Flowfield. Journal of Propulsion and Power 25.

Gruber, M. R., C. D. Carter, D. R. Montes, L. C. Haubelt, P. I. King and K. Y. Hsu (2008). Experimental Studies of Pylon-Aided Fuel Injection into a Supersonic Crossflow. Trans. Journal of Propulsion and Power 24, 460-470.

Gruber, M. R., J. M. Donbar, C. D. Carter and K. Y. Hsu (2004). Mixing and Combustion Studies Using Cavity-Based Flameholders in a Supersonic Flow. Trans. Journal of Propulsion and Power 20, 769-777.

Gruber, M. R., R. A. Baurle, T. Mathur and K. Y. Hsu (2001). Fundamental studies of cavitybased flameholder concepts for supersonic combustors. Trans. Journal of Propulsion and Power 17, 146-153.

Gugulothu, S. K. (2019). A systematic literature review based on different fuel injection strategies used in scramjet combustors. Trans. Heat Transfer: Asian Research 48, 3657-3681.

Haubelt, L. C., P. I. King, M. R. Gruber, C. D. Carter, D. R. Montes and K. Y. Hsu (2006, June). Performance of Pylons upstream of a Cavitybased Flameholder in non-reacting flow. In Proceedings of 42nd AIAA/ASME/SAE/ASEE Joint Propulsion Conference \& Exhibit, California.

Kyungjae Lee, S. K. (2012). Effects of Flameholder Configuration on a Staged Supersonic Combustor. Journal of Propulsion and Power 28(6), 1425-1428.

Liu, Y., M. Sun, C. Liang, J. Yu and G. Li (2019). Flowfield structures of pylon-aided fuel injection into a supersonic crossflow. Trans. ActaAstronautica 162, 306-313.

Nayal, S., S. Lamb, D, Sahoo, N. V. Raghavendra and S. A. I. Bellary (2020). Computational analysis of novel cavity-based flameholder designs for supersonic combustion engines. IOP Conference Series: Materials Science and Engineering 814.

Ouyang, H., W. Liu and M. Sun (2014). Investigations on the Influence of the In-Stream 
S. Nayal and D. Sahoo / JAFM, Vol. 14, No. 6, pp. 1635-1642, 2021.

Pylon and Strut on the Performance of a Scramjet Combustor, The Scientific World Journal, Article ID 309387, vol. 2014, 10 pages.

Ouzi Liu, J. C. (2010). Characteristics of Cavities in Reacting flows for Scramjet Flame-holder application. Modern Physics Letters B 24 (13), 1319-1323.
Pan Yu, D. J. (2014). Effect of scramjet combustor configuration on the distribution of transverse injection kerosene. Journal of Mechanical Science and Technology 28 (12), 4997-5002.

Vishnu, A. S., G. P. Aravind, M. Deepu and R. Sadanandan (2019). Effect of heat transfer on an angled cavity placed in supersonic flow. International Journal of Heat and Mass Transfer 141, 1140-1151. 